\title{
UMA ESTRATÉGIA PARA PROMOVER O TRABALHO CIENTÍFICO, TECNOLÓGICO E INOVADOR NO GABINETE PROVINCIAL DA EDUCAÇÃO DO HUAMBO, ANGOLA
}

\author{
João Baptista Machado Sousa* \\ https://orcid.org/0000-0003-0615-373X
}

\begin{abstract}
RECIBIDO: Julio 2020 / ACEPTADO: Septiembre 2020 / PUBLICADO: Enero 2021
\end{abstract}
Como citar: Sousa, João Baptista Machado. (2021). Uma estratégia para promover o trabalho científico, tecnológico e inovador no gabinete provincial da educação do Huambo, Angola. Telos: revista de Estudios Interdisciplinarios en Ciencias Sociales, 23 (1), Venezuela. (Pp.9-26).

DOI: www.doi.org/10.36390/telos231.02

\section{RESUMO}

O desenvolvimento de qualquer país passa necessariamente pela adopção de políticas que estejam alinhadas às suas necessidades sociais. Neste conjunto de políticas a serem estabelecidas, a área de Ciência, Tecnologia e a Inovação (CT\&l), não pode ser esquecida, por se configurar num espaço de especial destaque, sempre que de desenvolvimento se abordar. No presente trabalho abordam-se algumas concepções teóricas sobre a necessidade de se estabelecer uma Estratégia de Ciência, Tecnologia e Inovação exequível e sustentável que possa alavancar estas áreas nas escolas da província do Huambo, República de Angola. Assim sendo, o presente artigo pretende contribuir para literatura científica com o desenho de uma estratégia de CT\&I sustentável para a gestão dos processos substantivos do Gabinete Provincial de Educação e das escolas do ensino geral da província do Huambo. Para a elaboração da estratégia, tiveram-se em conta fundamentalmente os documentos normativos como: Assembleia Nacional (2011a), Assembleia Nacional (2011b), Assembleia Nacional (2011c), Assembleia Nacional (2018), MTTI (2019). Do ponto de vista metodológico utilizou-se o método de observação e análise documental, que favoreceu a revisão dos documentos normativos e, por via destes, fundamentar a estratégia. Utilizou-se também a modelação para o desenho da estratégia que se apresenta. Como resultado, obteve-se uma estratégia composta por etapas, acções e objectivos que podem, no entender do autor deste trabalho, pode promover o trabalho científico, tecnológico e inovador deste Gabinete do Huambo e generaliza-los para os demais contextos.

Palavras-chave: Estratégia; ciencia; tecnología; inovação; Huambo.

\footnotetext{
* Professor Auxiliar. Doutor. Chefe de Departamento de Ciência, Tecnologia e Inovação no Gabinete Provincial da Educação do Huambo. Email: sousangola@gmail.com
} 
Uma estratégia para promover o trabalho científico, tecnológico e inovador no gabinete provincial da educação do Huambo, Angola

\title{
Una estrategia para promover el trabajo científico, tecnológico e innovador en la oficina provincial de educación en Huambo, Angola
}

\section{RESUMEN}

El desarrollo de cualquier país implica necesariamente la adopción de políticas alineadas con sus necesidades sociales. En este conjunto de políticas por establecer, no se puede pasar por alto el área de Ciencia, Tecnología e Innovación (CT\&I), ya que se configura en un espacio de especial protagonismo, siempre que se aborde el desarrollo. En el presente trabajo se abordan algunas concepciones teóricas sobre la necesidad de establecer una Estrategia de Ciencia, Tecnología e Innovación factible y sostenible que pueda aprovechar estas áreas en las escuelas de la provincia de Huambo, República de Angola. Por tanto, este artículo pretende contribuir a la literatura científica con el diseño de una estrategia de CT\&I sustentable para la gestión de los procesos sustantivos de la Dirección Provincial de Educación y de las escuelas de educación general de la provincia de Huambo. Para la elaboración de la estrategia se tomaron en cuenta documentos normativos, tales como: Asamblea Nacional (2011a), Asamblea Nacional (2011b), Asamblea Nacional (2011c), Asamblea Nacional (2018), MTTI (2019). Desde el punto de vista metodológico, se utilizó el método de observación y análisis documental, que favoreció la revisión de documentos normativos y, a través de ellos, fundamentar la estrategia. También se utilizó la modelación para diseñar la estrategia presentada. Como resultado, se obtuvo una estrategia compuesta por etapas, acciones y objetivos que, en la opinión del autor, puede promover el trabajo científico, tecnológico e innovador de esta Oficina de Huambo y generalizarlos a otros contextos.

Palabras clave: Estrategia; ciencia; tecnología; innovación; Huambo.

\section{A strategy to promote scientific, technological and innovative work in the provincial office of education in Huambo, Angola}

\begin{abstract}
The development of any country necessarily involves the adoption of policies that are aligned with its social needs. In this set of policies to be established, the area of Science, Technology and Innovation (CT\&I) cannot be ignored, as it is configured in a space of special prominence, whenever development is approached. In the present work, some theoretical conceptions are approached about the need to establish a sustainable and feasible Science, Technology and Innovation Strategy that can leverage these areas in schools in the province of Huambo, Republic of Angola. Therefore, this article intends to contribute to scientific literature with the design of a sustainable CT\&I strategy for the management of the substantive processes of the Provincial Office of Education and of the schools of general education in the province of Huambo. For the elaboration of the strategy, normative documents were taken into account, such as: National Assembly (2011a), National Assembly (2011b), National Assembly (2011c), National Assembly (2018), MTTI (2019). From the methodological point of view, the method of documentary
\end{abstract}


observation and analysis was used, which favored the revision of normative documents and, through them, to substantiate the strategy. Modeling was also used to design the strategy presented. As a result, we obtained a strategy composed of stages, actions and objectives that, in our opinion, can promote the scientific, technological and innovative work of this Huambo Office and generalize them to other contexts.

Keyword: Strategy; science; technology; innovation; Huambo.

\section{Introdução}

A área de ciência, tecnologia e inovação (CT\&l) fornece as principais respostas para a construção da paz e para apoiar o desenvolvimento sustentável (Bokova, 2017). Com esta citação da directora-geral da Organização das Nações Unidas para a Educação, Ciência e Cultura (UNESCO), pretende-se enfatizar que há um processo acelerado de transformação em todos os sectores sociais que exigem uma adequação das políticas de cada país, para que seja possivel enfrentar os desafios actuais e futuros do Mundo, como resultado da evolução científica e tecnológica que se aproximam.

Neste sentido, o desenvolvimento de políticas sólidas de ciência, tecnologia e inovação, representa um dos instrumentos fundamentais para promover a produtividade, competitividade e desenvolvimento socioeconómico da sociedade em geral. Portanto, é essencial desenvolver políticas que fortaleçam as capacidades científicas e tecnológicas da nação, aumentem os níveis de progresso, bem como o bem-estar social de toda a população (Aguilar, 2017).

Desta forma, vêem-se incrementando políticas direccionadas à promoção da ciência, tecnologia e inovação (CT\&l), o que tem favorecido investimentos e propiciando investigações. $O$ sector da educação - entendido como aquela área social, responsável pela preparação do capital humano para enfrentar estes desafios - não se deve distrair. Muito pelo contrário, deverá estar sempre atento, e pronto para resolver ou propor soluções aos problemas mais candentes que a sociedade apresentar.

Ao nível internacional, existem diferentes investigações que realçam a necessidade e importância de se aprofundar e aproveitar a área CT\&l, como uma via excepcional, para o apoio ao desenvolvimento sustentável (Reis, 2001; Batista Zaldívar e Pérez Guerrero, 2007; Novaes e Carvalheiro, 2007; Silveira e Bazzo, 2009; De Andrade e Lopes, 2011; Aguilar, 2017; Artigas; Useche e Queipo, 2017; Bufrem, Silveira, e Freitas, 2018; Martínez Navarro, e outros, 2019).

Em Angola, visualizam-se documentos que regulam as aç̧ões das Tecnologias de Informação e Comunicação no País de forma geral, e especificamente de CT\&l e sua aplicação em todos os sectores sociais. Entre estes, destacam-se: Assembleia Nacional (2011a; 2011b; 2011c; 2018); MTTI (2019).

Apesar destes documentos apresentarem uma visão global dos desafios que 0 país enfrenta, abordam também, as principais estratégias de implementação e os seus respectivos mecanismos de coordenação. É no campo da educação, que se realiza esta investigação com intuito de se desenhar uma estratégia de CT\&I sustentável para a gestão dos 
Uma estratégia para promover o trabalho científico, tecnológico e inovador no gabinete provincial da educação do Huambo, Angola

processos substantivos do Gabinete Provincial de Educação e das escolas do ensino geral da província do Huambo.

Neste artigo apresenta-se algumas ideias que se consideram viáveis para a promoção do trabalho científica, tecnológico e inovador, onde se aborda o estado actual desta temática, e como se move em Angola; seguido da metodologia utilizada durante a investigação e finalmente a estratégia que tem como objectivo promover um conjunto de actividade de ciência, tecnologia e inovação de forma sustentável, que possa ser implementada no Gabinete Provincial de Educação e instituição para a gestão dos seus processos substantivos e generalizado noutros contextos.

\section{A promoção do trabalho científico, tecnológico e inovador em angola}

Para promover o trabalho científico é necessário que se criem condições que favoreçam a realização de investigação científica, como uma via para desenvolver qualquer sociedade. Neste quesito, Artigas; Useche e Queipo (2017), consideram que para organizar a geração de ciência e tecnologia requer infra-estruturas nacionais de desenvolvimento de conhecimento, pois, nestas estão incorporados as estruturas de intermediação, produtos de investigação, assim como mecanismos de estímulos, construção e fortalecimento de capacidades e competências técnico-científicas que contribuam para o desenvolvimento social.

Nesse sentido, as entidades responsáveis devem gerar políticas apropriadas de ciência, tecnologia e inovação que respondam oportunamente aos requisitos estabelecidos, 0 que somente será possível se houver dados precisos disponíveis, capazes de reflectir com maior eficácia o escopo e o impacto das actividades associadas a esse campo, propiciando assim bases úteis para orientar adequadamente as acções públicas e privadas destinadas a promover a construção de comunidades científicas, o fortalecimento da infra-estrutura de pesquisa, capital humano, pesquisa, desenvolvimento e capacidade de produção (Aguilar, 2017).

Sobre esta particularidade, a nível do Mundo identificam-se, com alguma facilidade, alguns países que se tem destacado neste campo, como o caso da China e Estados Unidos (National Science Board, 2020). Estes países investem anualmente, entre U\$ 409 milhões e U\$ 426 milhões de dólares para CT\&I. Em Angola, uma das principais dificuldades que limita o bom desempenho das CT\&I, reside nos orçamentos que são disponibilizados para este campo, que tem sido durante mais de 10 anos consecutivos inferior a 1\% do PIB (Ministério das Finanças, 2019). Por outro lado, a deficiente preparação dos recursos humanos também tem influenciado na insuficiente produção de ciência, de tecnologia e inovação que se verifica no país.

Não obstante, o governo angolano tem estado a trabalhar no sentido de se criar $\mathrm{e}$ implementar legislação necessária para alavancar estas áreas. Como resultado deste esforço, foram aprovados em Decretos Presidências, no ano de 2011, três diplomas que regulam: a política nacional de ciência, tecnologia e inovação; a estratégia nacional de ciência, tecnologia e inovação e, finalmente, os mecanismos de coordenação do sistema nacional de ciência. Concomitantemente, foram elaborados estudos como: indústria das Tecnologias de Informação e Comunicação em Angola, adiante designado por TIC, publicado no ano 2010, O Livro branco das TIC 2011-2018, publicado em 2011, o Plano Nacional da Sociedade de Informação 20132017, entre outros (Sousa, 2016, p.74). 
Como resultado da execução das orientações destes documentos, visualizam-se na sociedade angolana, desde 2010 até a actualidade, a realização de projectos como:

- Criação e ou actualização dos websites dos governos provinciais e central, com o objectivo de se facilitar o acesso a informação aos internautas;

- Projecto de governação electrónica, que irá permitir a interligação de todo aparelho do estado e facilitar desta forma a gestão dos processos substantivos ao Estado angolano;

- Criação de um Centro Nacional de Dados, com o objectivo de criar, manter e integrar uma estrutura física de tecnologia, que corresponda às exigências das estratégias do Estado angolano;

- Criação de um Parque Tecnológico para albergar empresas da área e desenvolver importantes actividades de investigação científica deste sector;

- Realização de um Forum Internacional de TIC por formas a se promover as potencialidades deste sector e promover a descoberta de novos Talentos;

- Criação de uma indústria nacional de hardware e software;

- Aposta na investigação científica, com auxílio da criação de centros de investigação científica que actuarão em correspondência com as Instituições Nacionais de Ensino Superior;

- Formação e qualificação dos recursos humanos na área das TIC;

- Fomento da cultura informática por parte da população angolana, com a criação de centros de formação e uma campanha de sensibilização para o uso das TIC (MTTI, 2012).

Apesar destas iniciativas, considera-se insuficiente a aplicação prática por parte dos Gabinetes Provinciais de Educação e consequentemente das escolas. Por este motivo, neste trabalho pretende-se destacar a visão do autor, no que concerne a implementação das CT\&I nos processos substantivos ao Gabinete Provincial de Educação do Huambo, assim como em todas as escolas da sua circunscrição; abordando algumas vias para auxiliar a concretização das orientações apresentadas nos documentos normativos que regulam a CT\&I em Angola, tendo em conta as tendências actuais movidas pelas dinâmicas sociais e, que pressionam 0 sector da educação ao seu cumprimento de forma coerente e harmonioso.

Propõe-se neste trabalho, objectivos, etapas e acções, critérios de medida e resultados esperados, os quais serão paulatinamente aperfeiçoadas e enriquecidas na medida em que forem implementadas e se assim se justificar.

Para esta investigação tiveram-se em conta, a revisão de documentos normativos do então Ministério da Ciência Tecnologia e Inovação e do Gabinete Provincial de Educação, bem como a observação realizada em algumas instituições de ensino da província do Huambo.

A estratégia de CT\&I que se apresenta neste trabalho, parte do princípio da elaboração de um documento formal, com ideias precisas que traduzam as aspirações do Governo angolano, em acções concretas a serem levadas a cabo pelo Gabinete Provincial da Educação do Huambo, por formas a se dar respostas às principais dificuldades identificadas nesta área.

A concepção estratégica de CT\&I corresponde tanto com os documentos normativos angolanos como com a experiência nacional e internacional e com as necessidades actuais de desenvolvimento deste sector. 
Uma estratégia para promover o trabalho científico, tecnológico e inovador no gabinete provincial da educação do Huambo, Angola

\section{Material e métodos}

Do ponto de vista metodológico utilizou-se o método de observação directa sistemático (Marconi e Lakatos, 2003, p.193), com a qual se realizou visitas de observações inspectivas a 50 escolas e utilizou-se como instrumento um guia de observação. Estas visitas tiveram como objectivo, a identificação dos projectos que envolvem CT\&l, os professores envolvidos nestes projectos, o seu nível de preparação, a existência de um plano de formação para estes professores e de manutenção para os equipamentos tecnológicos existentes, o tipo de software utilizado na gestão académica, identificação das bibliotecas e laboratórios e dos recursos humanos que os manejam, entre outros aspectos.

Por outro lado, realizou-se também uma análise documental, com fonte em arquivos públicos e tipo documentos escritos (Marconi e Lakatos, 2003, p.176), aos documentos normativos sobre ciência, tecnologia e inovação da República de Angola: Assembleia Nacional (2011a; 2011b; 2011c; 2018); MTTI (2019).

A análise documental foi utilizada com o objectivo de se perceber e comparar as intenções declaradas nos documentos normativos e a realidade prática das escolas. Foi possível identificar um conjunto de orientações e aspirações do Governo angolano para a implementação das políticas de CT\&I, nomeadamente: a massificação do uso das tecnologias por parte dos estudantes; a implementação de laboratórios de Física, Química e Biologia, para além de incrementar o número de bibliotecas escolares, de manuais e fortificar a preparação dos recursos humanos envolvidos neste processo.

Porém a realidade prática do Gabinete Provincial da Educação do Huambo e das escolas é diferente, na medida em que ainda se identificam inúmeras limitações para a efectivação destas aspirações. Finalmente, utilizou-se a modelação que auxiliou o autor desta investigação a desenhar a estratégia que se apresenta.

Como uma via para contribuir a solução dos problemas ora mencionados e por formas a auxiliar a concretização da política nacional de ciência, tecnologia e inovação, propõese a seguinte estratégia:

\section{Estratégia de ciência, tecnologia e inovação}

Assume-se que uma estratégia é um conjunto de acções sequenciais e interrelacionadas que partindo de um estado inicial (dado por um diagnóstico) permitem dirigir ao estado ideal, consequência da planificação (Valle Lima, 2010).

Em consequência, considera-se que uma estratégia de ciência tecnologia e inovação é, um conjunto de acções científicas, tecnológicas e inovadoras que tem a sua origem de um diagnóstico do estado inicial, o que permite caracterizar o objecto e encaminhar até a um estado ideal ou desejado como consequência de uma preparação dos actores envolvidos, da sua implementação e avaliação, tendo em conta os critérios de medidas e os resultados esperados.

Assim sendo, as acções que se propõem estão em estreita relação com os documentos normativos que regulam as acções de Ciência, Tecnologia e Inovação do Governo Angolano e vão dirigidas a contribuir na solução das insuficiências anteriormente mencionadas. Pretende-se que as mesmas sirvam de guia orientador aos membros do Gabinete Provincial de Educação do Huambo, Directores Municipais, Directores de Escolas e Professores. Para tal, 
propõem-se quatro etapas, que devem estar em estreita correspondência com os objectivo estabelecidos e as respectivas acções a desenvolver.

\section{Preparação para a implementação da estratégia de ciência tecnologia e inovação Estratégia base}

1. Promover a realização de conferências e seminários sobre ciência, tecnologia e inovação, suas potencialidades na gestão educativa por formas a despertar a consciência dos profissionais sobre a necessidade de implementação da estratégia ora desenhada;

2. Identificar os principais actores para a implementação da estratégia;

3. Elaborar uma cartilha sobre ciência, tecnologia e inovação.

\section{Implementação da estratégia de ciência tecnologia e inovação \\ Estratégia base}

1. Promover um encontro com os principais actores onde se poderá informar sobre as vias a utilizar para a implementação da estratégia de ciência, tecnologia e inovação;

2. Elaborar um referencial ocupacional onde se identifique que actividade irá realizar cada actor envolvido neste processo;

3. Elaborar um cronograma onde se definam o horizonte temporal para a implementação de cada acção;

4. Identificar as acções de Ciência, Tecnologia e Inovação que podem ser implementadas a curto, médio e longo prazo, com resultados visíveis e generalizáveis;

5. Desenhar e implementar uma plataforma educativa para favorecer o processo de formação dos agentes da educação na modalidade presencial, semi-presencial ou à distância e elevar o nível de preparação dos alunos do II ciclo do ensino secundário em conteúdos de informática;

6. Reparação e substituição paulatina dos equipamentos danificados, para garantir uma melhoria na qualidade das aulas de Informática, Biologia, Física e Química;

7. Identificar as escolas abrangidas pelos projectos tecnológicos como "TISA", "Meu Kamba" e "Pró-Futuro", constatar o nível de organização, certificar a qualidade do material existente e as classes abrangidas;

8. Conhecer os professores afectos aos projectos e identificar as dificuldades que apresentam no manuseio destes equipamentos;

9. Elaborar um plano de formação contínua que abranja todos os professores envolvidos nestes projectos e que aborde fundamentalmente sobre metodologias activas no ensino da informática;

10. Elaborar um plano de manutenção dos equipamentos tecnológicos existentes nas escolas;

11. Desenhar e implementar uma base de dados ou sistema de gestão escolar para todas as escolas da província do Huambo, com o objectivo de melhorar a eficiência da gestão escolar e uniformizar a informação académica das escolas do ensino primário, primeiro e segundo ciclo; 12. Desenhar e implementação de um sistema de gestão dos recursos humanos, com 0 objectivo de melhorar a gestão destes quadros da educação da província do Huambo;

13. Implementar a utilização de plataformas educativas nas escolas para facilitar o acesso aos conteúdos digitais e melhorar o preparo dos alunos;

14. Redesenhar a infra-estrutura de rede do gabinete provincial, por formas a garantir melhor qualidade de internet e segurança nos projectos que se pretendem implementar; 
Uma estratégia para promover o trabalho científico, tecnológico e inovador no gabinete provincial da educação do Huambo, Angola

15. Criar uma sala de impressão centralizada, por formas a reduzir-se custos com tinteiros e uniformizar a aquisição dos mesmos;

16. Desenhar e implementar um website para facilitar a difusão das informações do Gabinete;

17. Implementar um sistema de correio electrónico profissional para melhorar a qualidade e segurança da comunicação entre os agentes da educação;

18. Desenhar e implementar uma revista científica para favorecer a publicação de artigos científicos por parte de professores e investigadores da educação;

19. Realizar um simpósio anual onde se reflicta sobre os principais desafios da educação na Província do Huambo;

20. Realizar um concurso provincial de Física para a descoberta de novos Talentos na Disciplina de Física e o reforço da componente lúdica na aprendizagem desta disciplina;

21. Realizar uma feira anual das escolas técnico-profissional para promover as potencialidades do ensino técnico-profissional, num ambiente de interacção entre as instituições de ensino, empresas e comunidade.

\section{Avaliação ou controlo da estratégia de ciência tecnologia e inovação Estratégia base}

1. Constituir equipas para a avaliação do processo de implementação da estratégia;

2. Determinar os critérios de avaliação da estratégia;

3. Avaliar as acções e o cumprimento dos objectivos propostos;

4. Elaborar uma proposta de retroalimentação;

5. Actualizar a estratégia.

\section{Critérios de medida}

1. Identificação e estruturação os principais actores para a implementação da estratégia;

2. Elaboração de um referencial ocupacional onde se identifique que actividade irá realizar cada actor envolvido neste processo;

3. Elaboração de um cronograma onde se definam o horizonte temporal para a implementação de cada aç̧ão;

4. Identificação e estruturação das acções de Ciência, Tecnologia e Inovação que podem ser implementadas a curto, médio e longo prazo, com resultados visíveis e generalizáveis;

5. Identificação das escolas abrangidas pelos projectos tecnológicos como "TISA", "Meu Kamba" e "Pró-Futuro", constatação do nível de organização, certificação da qualidade do material existente e as classes abrangidas;

6. Domínio dos professores afectos aos projectos e identificação das dificuldades que apresentam no manuseio destes equipamentos;

7. Elaboração e ou desenho de um plano de formação contínua que abranja todos os professores envolvidos nestes projectos e que aborde fundamentalmente sobre metodologias activas no ensino da informática;

8. Elaboração de um plano de manutenção dos equipamentos tecnológicos existentes nas escolas;

9. Criação de uma sala de impressão centralizada, por formas a reduzir-se custos com tinteiros e uniformizar a aquisição de tonner. 
10. Redesenho da infra-estrutura de rede do gabinete provincial, por formas a garantir melhor qualidade de internet e segurança nos projectos que se pretendem implementar.

11. Desenho e implementação de um website para facilitar a difusão das informações do Gabinete;

12. Implementação de um sistema de correio electrónico profissional para melhorar a qualidade e segurança da comunicação entre os agentes da educação;

13. Desenho e implementação de uma plataforma educativa para favorecer o processo de formação dos agentes da educação na modalidade presencial, semi-presencial ou à distância e elevar o nível de preparação dos alunos do II ciclo do ensino secundário em conteúdos de informática;

14. Utilização de plataformas educativas nas escolas para facilitar o acesso aos conteúdos digitais e melhorar o preparo dos alunos;

15. Desenho e implementação de uma revista científica para favorecer a publicação de artigos científicos por parte de professores e investigadores da educação.

16. Desenho e implementação de uma base de dados ou sistema de gestão escolar para todas as escolas da província do Huambo, com o objectivo de melhorar a eficiência da gestão escolar e uniformizar a informação académica das escolas do ensino primário, primeiro e segundo ciclo; 17. Desenho e implementação de um sistema de gestão dos recursos humanos, com o objectivo de melhorar a gestão destes quadros da educação da província do Huambo;

18. Reparação e substituição paulatina dos equipamentos danificados para a melhoria da qualidade das aulas de Informática, Biologia, Física e Química;

19. Realização sistemática de um simpósio anual onde se reflicta sobre os principais desafios da educação na Província do Huambo

20. Realização sistemática de um concurso provincial de Física para a descoberta de novos Talentos na Disciplina de Física e o reforço da componente lúdica na aprendizagem desta disciplina;

21. Realização sistemática de uma feira anual das escolas técnico-profissional para promover as potencialidades do ensino técnico-profissional, num ambiente de interacção entre as instituições de ensino, empresas e comunidade.

\section{Resultados esperados}

1. Maior nível de organização dos principais actores para a implementação da estratégia e domínio do referencial ocupacional onde se destaque as actividades que cada membro envolvido deverá realizar e um cronograma com horizonte temporal para a implementação de cada acção;

2. Melhoria no controlo dos documentos impressos e uniformização dos tinteiros adquiridos;

3. Melhoria na segurança e qualidade de serviços de comunicação, internet no Gabinete Provincial de Educação.

4. Melhoria da qualidade de comunicação e difusão de informações do Gabinete Provincial de Educação;

5. Utilização de plataformas educativas e Implementação de novas modalidades de formação dos agentes da educação e elevação do nível de preparação dos alunos do II ciclo do ensino secundário em conteúdos de informática; 
Uma estratégia para promover o trabalho científico, tecnológico e inovador no gabinete provincial da educação do Huambo, Angola

6. Presença significativa de investigações realizadas pelos professores e publicadas em revistas científicas angolanas e estrangeiras;

7. Uniformização do sistema de gestão escolar para todas as escolas da província do Huambo, e melhoraria na emissão de certificados, declarações informações académicas;

8. Melhoria na gestão dos recursos humanos da educação da província do Huambo;

9. Melhoria significativa da qualidade dos equipamentos e das aulas de Informática, Biologia, Física e Química;

10. Reflexão permanente e contínua sobre os principais desafios da educação na Província do Huambo e propostas concretas sobre as vias para se debelar as insuficiências identificadas;

11. Descoberta de novos Talentos na Disciplina de Física e o reforço da componente lúdica na aprendizagem desta disciplina;

12. Maior valorização e interacção entre as escolas do ensino técnico-profissional, as empresas e a comunidade;

13. Melhoria significativa nas habilidades do ponto de vista tecnológico por parte dos professores que se manifestará no incremento da qualidade das aulas com recurso as tecnologia;

\section{Resultados e discussão}

Realizaram-se visitas de observação, pretendendo-se constatar o seguinte:

1. Projectos que envolvem CT\&l;

2. Nível de preparação dos professores envolvidos nestes projectos;

3. Existência de um plano de formação para os professores envolvidos nos projectos acima referenciados;

4. Existência de um plano de manutenção para os equipamentos tecnológicos existentes nas escolas;

5. Existência de softwares para gestão académica;

6. Identificação de bibliotecas e dos recursos humanos que os manejam.

\section{Sobre os projectos que envolvem CT\&I}

Gráfico 1. Número de escolas que albergam projectos de CT\&l

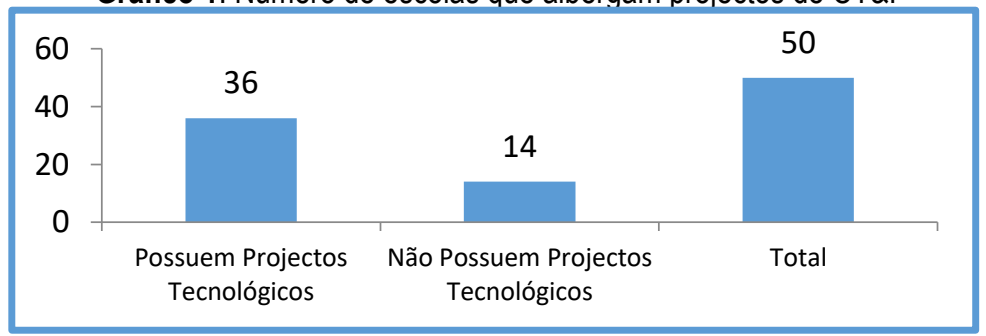

Fonte: elaboração própria

Como se pode verificar no gráfico acima, das 50 escolas observadas, 36 possuem projectos que envolvem tecnologia, nomeadamente "Pro-futuro" e "Meu Kamba" e 14 não possuem qualquer projecto. 
$O$ autor deste trabalho entende que existe grande necessidade de se massificar o uso das TIC, tendo em conta que maior parte dos estudantes actuais são "nativos digitais", ou seja, foram nascidos a partir da década de 80 ou mais tarde. 0 que os atribui certa facilidade no manejo deste equipamentos e uma determinada apreciação a estas ferramentas. Dai que estudiosos na matéria recomendam vincular a utilização dos computadores e dos recursos disponíveis na internet, com os conteúdos que leccionam, por formas a despertar maior interesse por parte dos estudantes.

Por outro lado, não há dúvidas que as TIC dinamizarem o processo de ensinoaprendizagem. Com a utilização de um computador e ou de um assistente matemático podemse resolver exercícios e representar os seus respectivos gráficos com grande nível de facilidade, precisão, e em muito menos tempo. Nesta perspectiva, Arnaiz Rey., Musholovela e González Fernández (2019), consideram que os alunos utilizam diariamente uma variedade de tecnologias e buscam o entretenimento através do computador, e este pode servir como suporte escolar para a realização de actividades em sala de aula que possibilitam a aprendizagem activa dos alunos ao permitir-lhes sentirem-se mais envolvido com os conceitos à medida que estes fazem uso da informática educativa para desenvolver as suas teorias.

Ponte (2002), relata que as TIC, são um meio fundamental de acesso à informação, são um meio de transformação e de produção de informação, constituem um meio de comunicação à distância, uma ferramenta para o trabalho colaborativo e promovem novas formas de interacção social. Martins (2009) acresce, afirmando que o desenvolvimento das TIC veio acrescentar a todo esse movimento uma verdadeira revolução no ensino.

Os investigadores acima mencionados, são unânimes em fundamentar a importância das TIC nas escolas, tendo em conta todas as vantagens que apresenta. $O$ autor deste trabalho, ratifica essa importância e considera que quanto maior for o número de projectos tecnológicos em funcionamento nas escolas, maior poderá ser o seu nível de desenvolvimento.

\section{Nível de preparação dos professores envolvidos nestes projectos}

Gráfico 2. Preparação dos professores para se desempenharem com tecnologia

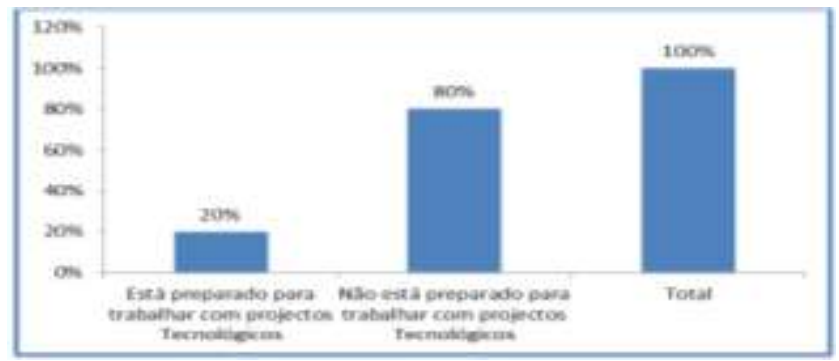

Fonte: elaboração própria 
Uma estratégia para promover o trabalho científico, tecnológico e inovador no gabinete provincial da educação do Huambo, Angola

Gráfico 3. Habilidades dos professores para se desempenharem com tecnologia

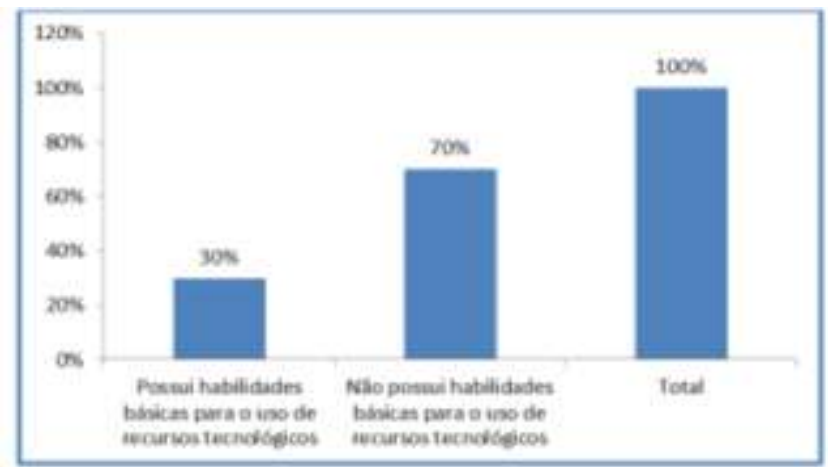

Fonte: elaboração própria

Os gráficos acima representam a percentagem de professores que possuem alguma preparação e habilidade para a utilização de recursos tecnológicos. Num total de 300 professores distribuídos pelas 50 escolas visitadas, maior parte (80\%) dos envolvidos em projectos não possuem um nível de preparação que os permita desenvolver aulas com qualidade; $20 \%$ possuem alguma preparação para o desenvolvimento das aulas com alguma qualidade. Do ponto de vista das habilidades básicas para o uso destes recursos tecnológicos (70\%) não possuem habilidades básicas para o uso destes recursos tecnológicos e (30\%) possuem habilidades básicas para o uso destes recursos tecnológicos, o que tem dificultado 0 cumprimento dos objectivos;

A preparação pedagógico-científica é condição fundamental para que um professor possa leccionar com êxitos. Infelizmente a falta de preparação dos professores é um processo recorrente em algumas escolas do país.

Apesar de que os professores consideram a profissão docente como a mais importante entre as demais, pois a formação de recursos humanos para as outras profissões depende grandemente da actuação dos profissionais da docência (Chissanguela, 2015), adicionado ao facto de que, muitos professores inqueridos possuem um conhecimento médio e basicamente teórico sobre as tecnologias educativas (Julião, 2020); os resultados revelam que, de forma geral, os professores, sejam estes do ensino público ou privado, não estão suficientemente preparados, o que implica um reconhecimento das limitações e inadequação nas competências do próprio professor para a sua actuação (Cardoso e Flores, 2009; Chissanguela, 2015).

Estas insuficiências se configuram nas principais dificuldades que limitam 0 bom funcionamento e um melhor desempenho tanto de professores como dos seus gestores escolares.

\section{Sobre o plano de formação para os professores envolvidos nos projectos acima referenciados}

Verificou-se, mediante a observação que não existe um plano de formação sistematizado para estes professores, naqueles conteúdos com maior dificuldade. Não obstante, 
as escolas visitadas afirmam terem realizado algumas formações arbitrárias, com apoio de alguns professores com maior domínio nos temas abordados.

A existência de um plano de formação contínua, sistematizado, é um dos requisitos para o sucesso educativo. A formação contínua como uma das funções da organização escolar, envolve tanto o sector pedagógico quanto o técnico e o administrativo (Libâneo, 2008, p. 227). Moreira (2002) considera a formação contínua, um direito do professor que precisa ser respeitado, visto que se trata de uma necessidade intrínseca à actuação desse profissional.

Bettega (2004, p. 38), afirma que a formação contínua do professor é significativa, pois visa corrigir distorções de sua formação inicial e também contribui para uma reflexão acerca de mudanças educativas que estejam ocorrendo. Independente das condições nas quais efectuou a formação inicial e da situação da escola em que lecciona, o professor precisa ter continuidade nos estudos, não apenas para ficar actualizado em sua área, mas pela própria natureza do fazer pedagógico.

Os autores acima referenciados permitem fundamentar a necessidade que um profissional tem de se auto-preparar, auto-superar, por formas a que consiga alcançar um melhoramento no desempenho das suas funções e no exercício da sua actividade profissional. Ao não existir, o processo pode ficar comprometido.

\section{Inexistência de um plano de manutenção para os recursos tecnológicos existentes;}

As observações realizadas permitiram identificar que $100 \%$ das escolas visitadas não possuem um plano de manutenção dos equipamentos, estando sujeitos a intervenções sempre que manifestar mau funcionamento.

Existem várias categorias de manutenção de equipamentos, entre estas, destacamse: a manutenção correctiva não planejada, correctiva planejada, preventiva, predita, detectiva e engenharia de manutenção. Para este caso, o plano de manutenção deve fazer referência a manutenção preventiva e preditiva, com o objectivo de se realizar inspecções rotineiras para identificação de irregularidades nos equipamentos e garantir o seu bom desempenho.

A inexistência de um plano de manutenção faz com que os equipamentos instalados possam, com alguma facilidade, entrar em estado de degradação. Por outro lado, a existência de um plano de manutenção dos equipamentos revela-se numa via credível para garantir a segurança, confiabilidade, melhorar a qualidade e aumentar a produtividade de quem utiliza.

Olarte; Botero e Cañon (2010), consideram que para se cumprir com estándar regionais, nacionais ou internacionais de qualidade, é indispensável que as instituições contem com um apropriado plano de manutenção que os permita conservar os seus equipamentos, ferramentas e instalações nas melhores condições de funcionamento. 
Uma estratégia para promover o trabalho científico, tecnológico e inovador no gabinete provincial da educação do Huambo, Angola

\section{Sobre a existência de software para gestão académica}

Gráfico 4. Uso de software de gestão nas escolas visitadas

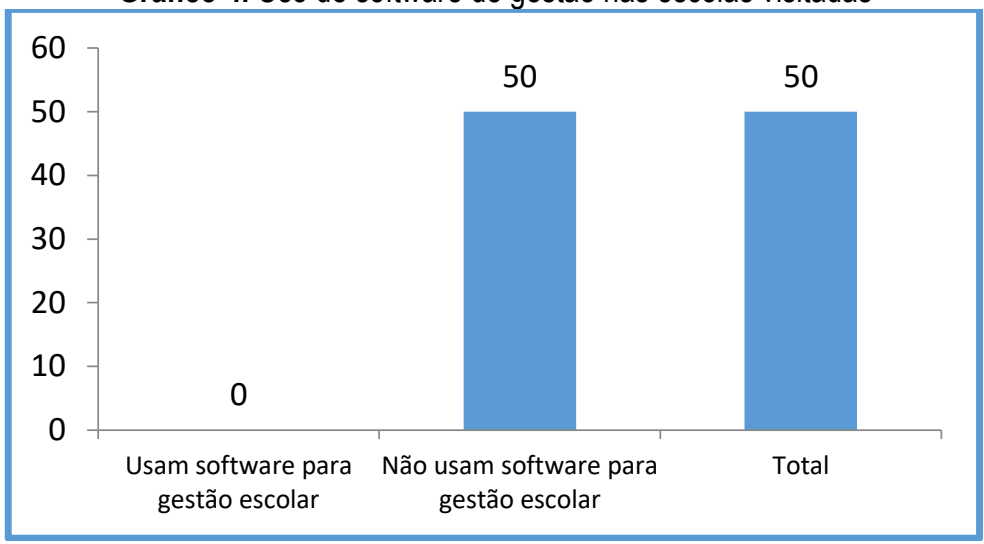

Fonte: elaboração própria

Como se pode verificar no gráfico acima, das 50 (cinquenta) escolas visitas, não se observou em nenhuma delas, a utilização de um sistema de gestão escolar mas sim de planilhas electrónicas não uniformizadas.

Para se gerir com êxito uma instituição de ensino, é fundamental a existência de um software de gestão escolar, na medida em que permite a automatização das tarefas e economia de tempo. Sánchez Pacheco (2016), realizou uma investigação intitulada "importancia del software educativo en la gestión académica - administrativa de la unidad educativa Alonso Veloz Malta", onde concluiu que a os estudantes consideram que a gestão académica - administrativa realizada manualmente produz um resultado deficiente; contudo os professores aconselham a utilização das TIC na gestão destes processos por formas a obter-se resultados mais significativos (p.26).

Peirats Chacón \& Sales Arasa (2009, p. 90), considera que as tecnologias existentes nas escolas são produto do seu tempo e devem ser acomodados junto com os restantes recursos. Assim sendo, em algumas escolas do município sede, verificou-se a existência de grandes quantidades de computadores, e, em algumas circunstâncias, conexões à rede local. Estas, podem ser consideradas como condições básicas para a implementação de um Sistema de Gestão que vise melhorar a produtividade académica nas escolas da província do Huambo.

\section{Sobre as insuficientes bibliotecas escolares}

Das 50 (cinquentas) escolas visitadas, não se verificou a existência de bibliotecas. As bibliotecas escolares conformam um espaço de socialização académico-científica e de constatação de informações dissertadas pelos professores em sala de aulas. Quando uma instituição escolar não possui biblioteca, este processo de constatação e diversificação de literatura fica comprometido. 
A este respeito, Perucchi (1999), explica que "para que os objectivos da educação possam ser atingidos, é necessário que os meios utilizados sejam compatíveis e eficazes. Portanto, entre os diversos recursos educativos encontra-se a biblioteca, considerada um recurso indispensável para o desenvolvimento do processo de ensino-aprendizagem e formação do educando-educador" (p. 82)

As bibliotecas escolares são extremamente importantes na edificação do conhecimento humano e nesta conviç̧ão, um dos objectivos que pretendem atingir é conduzir os cidadãos a um contacto permanente com a informação (Rodrigues, 2010).

Não obstante, Rodrigues (2010), ao referir-se a Calixto (1996, p. 119), considera que a ausência de uma biblioteca escolar penaliza gravosamente os alunos das classes mais desfavorecidas, pois 0 ambiente familiar não só não lhes propicia o acesso aos livros e a um ambiente familiar literato como, com o desenvolvimento de novas tecnologias, não têm acesso a computadores e a todas as enormes vantagens que daí advêm em termos de acesso à informação.

Silva; Enns \& Inowlocki (2013), consideram que (...) "existe necessidade das biblioteca escolares estarem bem definidas e organizadas, do ponto de vista do seu funcionamento para facilitar tanto 0 ensino quanto a aprendizagem de alunos e professores" (...) (p. 17128). Concorda-se com Rodrigues (2010), quando afirma que a biblioteca escolar deve servir como espaço de democratização, ao nivelar as desigualdades sociais e culturais existentes entre os alunos, fornecendo a todos os professores, sem excepção, os mesmos recursos e oportunidades.

Em síntese o diagnóstico realizado entre os meses de Outubro de 2019 a Fevereiro de 2020, tanto ao nível das visitas inspectivas como na análise aos documentos normativos, permitiu identificar os principais problemas existentes na área de ciência, tecnologia e inovação. Destes, destacam-se os seguintes:

- Necessidade dum adequado e uniformizado sistema de gestão escolar para se uniformizar os procedimentos académicos, pautas e certificados das escolas da província do Huambo;

- Necessidade dum adequado sistema de gestão dos recursos humanos para educação;

- Insuficiente preparação do capital humano para enfrentar os desafios que se impõem ao nível da CT\&l;

- Insuficiente preparação do capital humano para a gestão das bibliotecas ao nível das escolas; - Insuficientes laboratórios e capital humano preparado para a gestão dos laboratórios já existentes, o que impossibilita o cumprimento de um dos mais importantes princípios didáctico, que é "a relação da teoria com a prática";

- Necessidade de se incrementar actividades onde se aproveitem e se massifique a utilização das tecnologias de informação e informação;

- Insuficiente aproveitamento das TIC, para a gestão dos processos substantivos do Gabinete Provincial da Educação do Huambo;

- Necessidade de um plano de formação contínua para a preparação dos professores envolvidos em projectos tecnológicos;

- Necessidade de um plano de manutenção dos equipamentos tecnológicos existentes nas escolas do ensino geral da província do Huambo; 
Uma estratégia para promover o trabalho científico, tecnológico e inovador no gabinete provincial da educação do Huambo, Angola

Assim sendo, com este diagnóstico realizado e com a proposta de estratégia de Ciência, Tecnologia e Inovação, pretende-se levar a cabo um processo de socialização e implementação por formas a se debelarem as insuficiências ora identificas.

\section{Considerações finais}

Depois de realizado uma descrição sobre os processos de ciência, tecnologia e inovação da República de Angola, percebe-se que há uma intenção por parte do governo deste país em melhorar significativamente as condições de trabalho, entre estas destacam-se: as legislações e documentos normativos, as infra-estruturais e os recursos humanos com 0 objectivo de se alcançar índices de desenvolvimento mais aceitáveis; Não obstante a esta intenção, considera-se que deve haver um melhoramento nos orçamentos destinado para esta finalidade;

A aplicação dos métodos de observação e da análise documental, permitiu identificar as principais debilidades que limitam a implementação das orientações do Governo de Angola com êxitos, plasmados fundamentalmente nos documentos que regulam as actividades de CT\&I por parte do Gabinete Provincial de Educação do Huambo e das escolas desta cidade;

Em função destas debilidades identificadas, desenhou-se uma estratégia de CT\&I, composta por acções, critérios de medida e resultados esperados, que traduzem as aspirações do Governo angolano e, a nosso modo de ver, podem auxiliar a implementação e avaliação das acções de CT\&I no Gabinete Provincial da Educação do Huambo;

\section{Referencias bibliográficas}

Aguilar, Marly. (2017). Indicadores de ciencia, tecnología e innovación en Venezuela y su impacto en el desarrollo de políticas públicas. Telos: revista de Estudios Interdisciplinarios en Ciencias Sociales. Volume. 19. Número. 1. Venezuela. (Pp.119146).

Arnaiz Rey, Anay; Musholovela, José da Silva Alfredo., e González Fernández. (2019). A virtualização no processo de ensino - aprendizagem das ciências exactas. RAC: Revista Angolana de Ciências, Volume 1. Número. 1. Angola. (Pp.117-135).

Artigas, Wileidys; Useche, María Cristina y Queipo, Beatriz. (2017). Sistemas nacionales de ciencia y tecnología de Venezuela y Ecuador. Telos: revista de Estudios Interdisciplinarios en Ciencias Sociales. Volume. 19. Número. 1. Venezuela. (Pp. 168187).

Assembleia Nacional. (2011a). Decreto Presidencial 196/11, de 11 Julho de 2011. Aprova a Estratégia Nacional de Ciência, Tecnologia e Inovação. Diário da República I série 130. Assembleia Nacional. (2011b). Decreto Presidencial 201/11 de 20 Julho. Aprova a Política Nacional de Ciência, Tecnologia e Inovação de Angola. Diário da República I série 137. Assembleia Nacional. (2011c). Decreto Presidencial 224/11, de 20 Agosto de 2011. Estabelece os Mecanismos de coordenação do Sistema Nacional de Ciência, Tecnologia e Inovação. Diário da República I série 153.

Assembleia Nacional. (2018). Ministério da Economia e Planeamento. (2018). Plano de Desenvolvimento Nacional 2018-2022. Volume I. MEP. Angola.

Batista Zaldívar, Mario., \& Pérez Guerrero, Julio. (2012). Propuesta de una metodología para la gestión de la ciencia y la innovación en una filial universitaria municipal cubana. Revista 
Cubana De InformacióN En Ciencias De La Salud. Volume 23. Número. 3. Cuba. (Pp. 279-294).

Bettega, Maria Helena. (2004). A educação continuada na Era Digital. Cortez. Brasil

Bokova, Irina (2017). UNESCO: ciência e tecnologia dão respostas para a construção do desenvolvimento sustentável. Disponível: https://nacoesunidas.org/unesco-ciencia-etecnologia-dao-respostas-para-a-construcao-do-desenvolvimento-sustentavel/

Bufrem, Leilah Santiago., Silveira, Murilo. e Freitas, Juliana Lazzarotto. (2018). Políticas de ciência, tecnologia e inovação no brasil: panorama histórico e contemporâneo. P2P \& Inovação. Volume 5. Número 1. Brasil. (Pp.6-25).

Cardoso, Ermelinda Monteiro Silva. \& Flores, Maria Assunção. (2009). A formação inicial de professores em angola: problemas e desafios. Actas do X Congresso Internacional Galego-Português de Psicopedagogia. Braga. Portugal

Chissanguela, Tadeu Calandula. (2015). Perfil do Professor Angolano do Ensino Primário: Contributo para um Estudo Comparativo no Município de Belas - Colégio Pitruca e Escola Pública Pedalé. Dissertação de Mestrado. Universidade de Évora. Portugal.

De Andrade, Jailson Bittencourt e Lopes, Wilson Araújo. (2011). Conectando ciência, tecnologia e inovação. Parcerias Estratégicas. Volume. 16. Número. 32. Brasil. (Pp. 385-401).

Julião, António Luís. (2020). Professores, tecnologias educativas e COVID-19: realidades e desafios em Angola. RAC: Revista Angolana de Ciências. Volume. 2. Número. 2. Angola. (e020205).

Libâneo, José Carlos. (2008). Organização e gestão da escola: teoria e prática. 5. Ed. Revista e ampliada. MF Livros. Brasil

Marconi, Maria de Andrade., e Lakatos, Eva Maria. (2003). Fundamentos de metodologia científica. 5. Edição. Atlas Editora. Brasil.

Martínez Navarro, Marlene., e outros. (2019). Gestión social de la ciencia, tecnología e innovación: Trayectorias y desafíos en la universidad cubana. Editorial Académica Espanhola. Espanha

Martins, Zélia. (2009). As TIC no ensino-aprendizagem da matemática. Actas do X Congresso Internacional Galego-Português de Psicopedagogia. Braga. Portugal.

Ministério das Finanças. (2019). Orçamento geral do estado 2019. Disponível em: https://www.minfin.gov.ao/PortalMinfin/\#!/materias-de-realce/orcamento-geral-doestado/oge-do-ano-corrente

Moreira, Carlos Eduardo. (2002). Formação continuada de professores: entre o improviso e a profissionalização. Insular. Brasil.

MTTI. (2012). Estudos prévios à necessidade de implementação de medidas de desenvolvimento e promoção da indústria nacional do sector das TIC em Angola. Disponível em:

content/uploads/2012/05/Industria_TIC_Nacional.pdf

http://mediatecas.ao/wp-

MTTI. (2019). Livro Branco das Tecnologias de Informação 2018-2022. Ministério das Telecomunicações e Tecnologias de Informação. Angola.

National Science Board. (2020). Science and Engineering Indicators 2018. NSB-2018-1. Alexandria, VA: National Science Foundation. Available at https://www.nsf.gov/statistics/indicators/ 
Novaes, Hillegonda Maria Dutilh \& Carvalheiro, José da Rocha (2007). Ciência, tecnologia e inovação em saúde e desenvolvimento social e qualidade de vida: tese para debate. Ciência \& Saúde Coletiva. Volume. 12 (Sup). Brasil. (Pp.1841-1849).

Olarte, William; Botero, Marcela; Cañon, Benhur. (2010). Importancia del mantenimiento industrial dentro de los procesos de producción. Scientia Et Technica, Volume. XVI. Número. 44. Colombia. (Pp.354-356).

Peirats Chacón, José; Sales Arasa, Cristina. (2009). Inquietudes y complicidades en el uso del software de gestión en centros educativos. Education in the Knowledge Society (EKS). Volume. 10. Número. 1. Espanha. (Pp. 76 - 92).

Perucchi, Valmira. (1999). A importância da biblioteca nas escolas públicas municipais de Criciúma- Santa Catarina. Revista ACB: biblioteconomia. Volume. 4, Número. 4. Brasil. (Pp. 80-97).

Ponte, João. Pedro. (2002). As TIC no início da escolaridade: Perspectivas para a formação inicial de professores. In João. Pedro. Ponte (Org.), A formação para a integração das TIC na educação pré-escolar e no $1 .^{\circ}$ ciclo do ensino básico. Porto Editora. Portugal

Reis, Márcia Lopes. (2001). Processos de inovação e políticas de ciência e tecnologia: um olhar sobre a função social da escola brasileira na contemporaneidade. Sociologias. Volume 6. Brasil. (Pp.52-69).

Rodrigues, Anabela da Conceição Afonso. (2010). A importância da Biblioteca Escolar para a Literacia da Informação. As Bibliotecas Escolares do $2^{\circ}$ e $3^{\circ}$ ciclos do Distrito de Bragança. Dissertação de Mestrado. Universidade Fernando Pessoa. Portugal.

Sánchez Pacheco, Carlos Luis. (2016). Importancia del software educativo en la gestión académica -administrativa de la unidad educativa Alonso Veloz Malta. Universidad de Guayaquil. Equador

Silva, Eliane de Souza; Enns, Udo; Inowlocki, Márcia Pavelski. (2013). A importância da biblioteca escolar no contexto educacional da escola do campo no município de araucária no estado do Paraná. XI Congresso de educação. EDUCERE. Curitiba. Brasil

Silveira, Rosemari Monteiro Castilho Foggiatto e Bazzo, Walter. (2009). Ciência, tecnologia e suas relações sociais: a percepção de geradores de tecnologia e suas implicações na educação tecnológica. Ciência \& Educação. Volume.15. Número. 3. Brasil. (Pp. 681694).

Sousa, João Baptista Machado. (2016). Impacto das Tecnologias de Informação e Comunicação nolnstituto Superior de Ciências da Educação do Huambo, Angola. REFCalE. Volume.

4. Número 3. Equador. (Pp. 71-76).

Valle Lima, Alberto. (2010). La investigación pedagógica otra mirada. ICCP. Cuba 